\title{
El protagonismo de las mujeres en las cadenas de producción y comercialización de las rosquillas Somoteñas
}

\author{
Marissa Olivares ${ }^{1}$, Fabiola Alvarado A². y Jahaira V. Rivera M.² \\ 1. Dirección de Postgrado, Universidad Centroamericana (UCA). Apartado 69. Managua, Nicaragua. \\ e-mail:marissao@ns.uca.edu.ni \\ 2. Egresadas de la carrera de Trabajo Social. Facultad de Humanidades (UCA) . Apartado 69. Managua, Nicaragua.
}

Recibido: abril, 2005 / Aceptado: junio, 2005

EL ESTUDIO SOBRE EL COMERCIO DE LAS ROSQUILLAS SOMOTEÑAS SE realizó con el propósito de entender el funcionamiento de las cadenas de producción y comercialización del producto, identificar los factores que influyen en la formación del precio y analizar el rol de los actores sociales a lo largo de las cadenas. Se encontraron tres cadenas de producción y comercialización y se descubrió que, desde el punto de vista institucional, la producción de rosquillas no se considera una actividad económica porque son mujeres quienes la realizan, por el tipo de gerencia que las rosquilleras desarrollan y por su origen y permanencia en el ámbito doméstico.

Palabras clave: mujeres-aspectos socioeconómicos, rosquillas-mercados

\section{Propósito y relevancia del tema de investigación}

El estudio de las cadenas de producción de rosquillas somoteñas es relevante en el contexto actual, porque es una experiencia importante a tener en cuenta para el análisis y definición de estrategias económicas, con el enfoque de cadenas productivas o cadenas de valor.

Este estudio se realizó con el propósito de analizar y evidenciar las experiencias endógenas que hay en el país, que han surgido y se han desarrollado desde las iniciativas de los actores sociales inmersos en el proceso productivo y de comercialización. La producción y comercialización de rosquillas somoteñas surge y se mantiene desde los años 50, en un contexto donde las políticas de fomento al sector y las iniciativas de ONGs han estado ausentes.

\section{Introducción}

Somoto goza de reconocimiento y fama como el Municipio donde se producen las "mejores rosquillas"3 del país. No obstante, la actividad no es considerada como actividad 
económica importante para la economía del país, pese a que es el principal -y en la mayoría de los casos el único- ingreso económico para las 17 familias integradas a los talleres de producción en el casco urbano de Somoto, y para todas las personas que participan en la actividad (proveedores, comerciantes, vendedores de servicios diversos).

Estas cadenas se sitúan en un contexto de economía dependiente y de reducción del gasto público, muy influenciado por el modelo neoliberal que enfatiza el libre mercado como mecanismo promotor del desarrollo, invisibilizando las iniciativas locales.

El desarrollo de la actividad responde a una dinámica propia de los actores y la zona -la experiencia y tradición apoyada por un modo organizativo-, más que por tecnología mecanizada para procesar y distribuir, o un esfuerzo particular del Estado. Es una actividad "subestimada" de parte de diversos actores, incluyendo las dueñas de los talleres.

La clave para que esta actividad haya perdurado a lo largo de 54 años, aproximadamente, se debe, entre otras cosas, a que las personas involucradas invierten sus propios recursos, dependen exclusivamente de su realización para el sustento de sus familias y de que se insertan en ella por su propia iniciativa y necesidades, más que por interés de acumular o por iniciativa de agentes externos. Dichos actores tienen un medio para vender el producto que se basa en las distintas relaciones sociales y en su evolución.

\section{Sentido y objeto de la investigación}

El interés de abordar esta temática nace de los resultados del estudio de país realizado por investigadores de Nitlapán sobre las actividades económicas que generan ingresos familiares, donde se encontró que la producción de rosquillas somoteñas es una de las principales actividades del Municipio.

Antes de este estudio, en nuestro país no se habían hecho investigaciones sobre este tipo de actividades para evidenciar su importancia por el empleo directo e indirecto que generan, la participación de sus actores y las relaciones sociales que se desarrollan entre ellos.

El comercio se relaciona históricamente con la economía, pero también con la dinámica de los actores involucrados, porque son los seres humanos los que realizan las actividades de producción y comercialización, donde se producen relaciones e interacciones entre los sujetos sociales dentro de un contexto específico. Para el análisis de los resultados del estudio, se ha considerado a los actores sociales como participantes de procesos socio-organizativos.

Al estudiar esta actividad desde los sujetos sociales, se comprenden mejor el comportamiento, motivaciones, necesidades y estructura de la relaciones sociales de los actores involucrados en la actividad, lo que implica la búsqueda de otros conocimientos diferentes a los que proporciona la economía clásica, que no ve a los actores, sino los resultados en términos de capital, rentabilidad y acumulación.

Por todo ello, se trabajó con la hipótesis de que "las cadenas de producción y comercialización de las rosquillas funcionan como producto de las relaciones sociales 
entre actores sociales claves, quienes establecen alianzas para la producción y venta del producto”.

\section{Materiales y métodos}

Para la realización de este estudio, se hizo una combinación de métodos cuantitativos con cualitativos, que permitió el balance de la información obtenida. El estudio de las cadenas se hizo desde el enfoque del análisis subsectorial.

\section{Los instrumentos utilizados:}

\section{La encuesta}

La encuesta facilitó el conocimiento del número de talleres y personas que participan en cada operación, la formación de los precios, la inversión que se realiza en la producción y comercialización del producto, destino, proveedores, intermediarios y consumidores.

La información obtenida con la encuesta permitió graficar las cadenas de comercialización de las rosquillas somoteñas, agrupando los talleres en tres bloques que más adelante se denominan "cadenas". Estas agrupaciones fueron determinadas por los criterios de selección aplicados:

Estructura organizativa para la venta del producto, es decir, la ruta de venta, destino y estrategia que cada dueña de taller utiliza para vender las rosquillas, con o sin intermediarios.

\section{Las entrevistas semiestructuradas}

Este instrumento proporcionó información cualitativa para analizar los factores que han hecho posible la permanencia de la actividad y los tipos de arreglos, alianzas y acuerdos que se desarrollan a lo interno de la actividad. Se entrevistó a tres dueñas de talleres, a su principal proveedor (el de queso o cuajada), al conductor de bus inter urbano y a las intermediarias, para analizar las relaciones sociales que se producen entre estos.

Para analizar las relaciones sociales que se producen entre los principales actores que participan en las cadenas, se seleccionaron tres casos (talleres) cuyos criterios fueron:

- Que representaran las relaciones o vínculos más estables.

- Que fueran representativos de las cadenas.

\section{La observación}

La observación in situ fue otro instrumento de la investigación para agregar elementos que ayudaron a la interpretación y análisis de los resultados del estudio.

Se contó con una amplia revisión teórica y asesoría de profesionales (investigadores de Nitlapán) para la comprensión y análisis del tema estudiado. 
En la interpretación y análisis de los resultados del estudio, se usaron distintos planteamientos sobre los diferentes conceptos: i) el sector informal y su relación con los procesos de las pequeñas industrias artesanales; ii) el concepto de cadenas, que incluye los distintos eslabones por los que pasa el producto desde su concepción hasta su consumo, en el que se analiza con mayor profundidad el comercio, mercado, rol de los actores sociales, sus relaciones sociales, los lazos fuertes y débiles que les unen, y la gobernabilidad en su interior; iii) y Habitus, Campo y perspectiva de género, como la macro dimensión social en que se desarrolla el proceso de comercialización.

\section{Resultados}

\subsection{Ubicación de los talleres de rosquillas}

En el cuadro 1, se ve que los 17 talleres ubicados en el casco urbano de Somoto están concentrados geográficamente, por lo que se asemejan a pequeños clusters o agrupamientos productivos en los que se producen diversos tipos de interacciones sociales que hacen posible el desarrollo de cada una de las actividades de las cadenas.

Cuadro 1. Ubicación de talleres casco urbano Somoto.

\begin{tabular}{|l|l|}
\hline Barrio/sector & Total \\
\hline Barrio Pancasán. Sector 1 & 8 \\
\hline Orlando López. Sector 4 & 6 \\
\hline Raúl Zapata. Sector 8 & 1 \\
\hline Julio Ramos. Sector 14 & 1 \\
\hline Luis Alfonso Velázquez. Sector 10 & 1 \\
\hline Total & 17 \\
\hline
\end{tabular}

Fuente: elaboración propia sobre la base de entrevistas a las dueñas de los talleres

Esta concentración favorece la disminución en los costos de transporte para el abastecimiento y comercialización del producto final, porque los oferentes de insumos y materia prima, en general, llegan a vender sus productos a esos lugares; asimismo, los transportistas llegan a cargar los canastos para hacer la entrega en los mercados capitalinos.

Por otro lado, la concentración de los negocios facilita el acceso de turistas y clientes nacionales y extranjeros, porque la población local conoce de su existencia y ubicación.

Los talleres surgen, se organizan y desarrollan desde la iniciativa del conjunto de personas que se involucran en la actividad, motivadas por la necesidad de colocar sus productos y/o percibir un ingreso para sus hogares.

Desde la perspectiva del análisis subsectorial (Parilli: 2002) los talleres de rosquillas no son entidades aisladas que funcionan de manera independiente, sino eslabones que forman parte de distintos canales de producción y comercialización. 


\subsection{Las Cadenas}

Una cadena es una red de trabajo y proceso de producción cuyo resultado constituye un producto terminado. Existen dos niveles para identificar una cadena, su constitución y la relación y vinculación entre distintas cadenas ligadas al mismo producto (Mendoza, 2002:18).

Los datos de la encuesta y entrevistas llevan a configurar tres cadenas de producción y comercialización de rosquillas. Esta actividad se caracteriza porque está a cargo de mujeres; el proceso productivo corre por cuenta propia; y se desarrolla en el ámbito doméstico.

Estas cadenas operan sin financiamiento de ninguna agencia financiera ni ONG, lo que confirmó la hipótesis, pues las cadenas funcionan como resultado de las interacciones sociales entre los diferentes actores participantes en la actividad (ver ilustración 1).

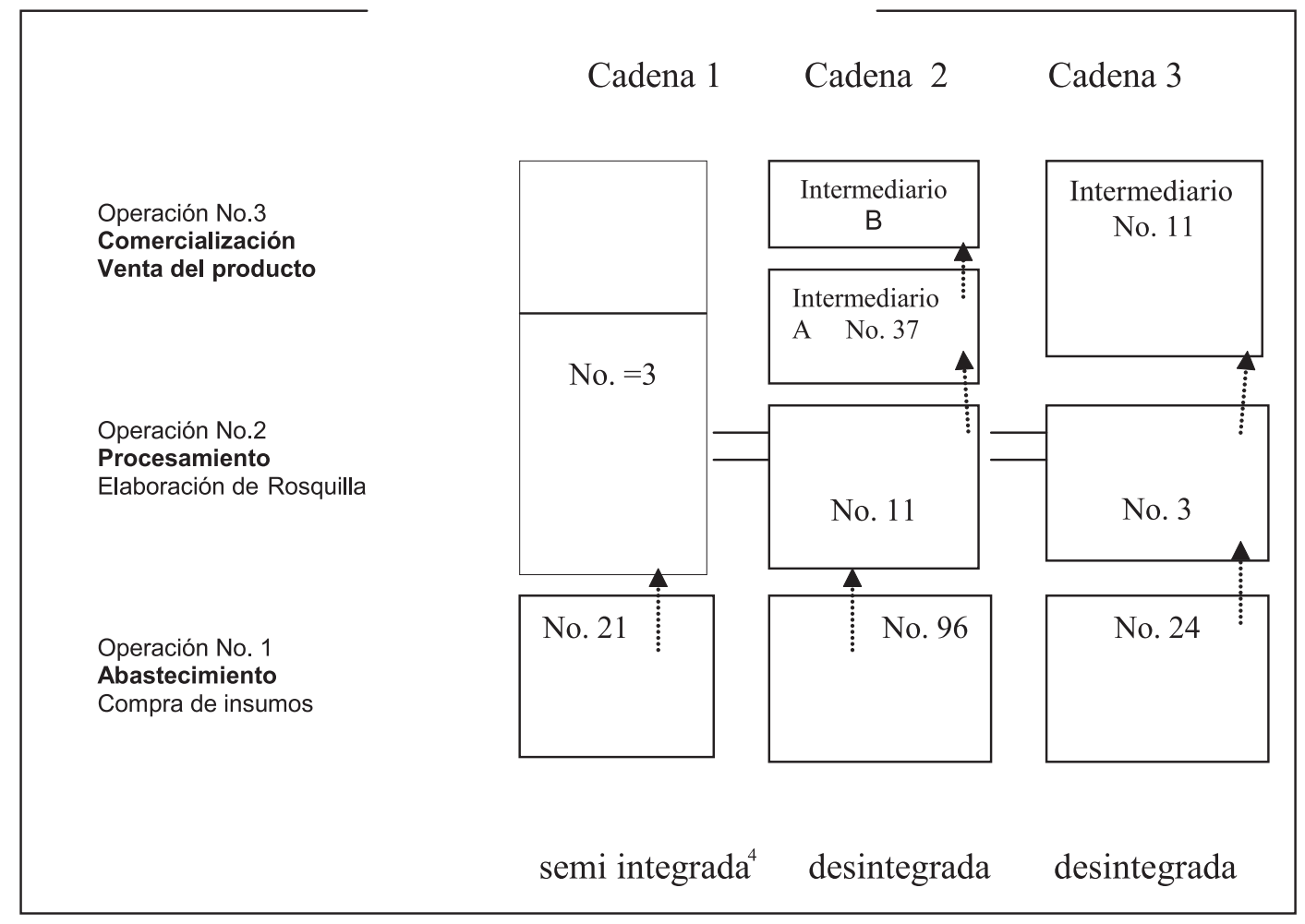

Ilustración 1. Cadenas en la comercialización de las rosquillas Somoteñas.

Leyenda:

Venta del producto ; $=$ Semejanzas en tecnología; $\square$ División entre una operación y otra ;

División entre una operación y otra dentro del mismo taller

Número: cantidad de personas que participan por operación, con excepción en la operación dos donde el número corresponde al total de talleres existentes.

Fuente: elaboración propia sobre la base de entrevistas a las dueñas de los talleres, a comerciantes y conductores de buses. 
El enfoque de cadena permite identificar la actividad como un conjunto articulado, y no como actividades o empresas dispersas que funcionan de manera independiente. Además, el enfoque permitió analizar y comparar cada cadena con las otras y visualizar las oportunidades que tiene cada una de permanecer en el mercado e insertarse en nuevos segmentos de mercados.

Se pudo identificar que no hay cooperación /colaboración entre cadenas; sólo cuando las dueñas tienen lazos familiares, se producen relaciones de cooperación /colaboración intra cadenas.

\subsection{Las diferencias entre las cadenas consisten en:}

Tienen distintos mecanismos de venta. La cadena 2 , es la que se encuentra mejor conectada con el mercado "Roberto Huembes" de la capital, al que acuden turistas y consumidores en general, con cierto poder adquisitivo, que les permite pagar el precio de las rosquillas de Somoto.

En cambio, la cadena 1 no cuenta con intermediación comercial, porque las dueñas de los talleres venden el producto directamente al consumidor final.

En la cadena 3, aunque existe intermediación, las mujeres comercializan de forma ambulante, las ventas son inestables y con poca tendencia al crecimiento. Es decir, no tienen una clientela fija a la que ofrecer su producto. La venta se realiza a pie; estas mujeres cargan los canastos o panas con rosquillas sobre la cabeza.

En el análisis vertical de las cadenas, se identificaron algunos aspectos relevantes que se resume en el cuadro 2.

Cuadro 2. Aspectos relevantes de las cadenas

\begin{tabular}{|c|c|c|c|}
\hline Criterios & Cadena 1 & Cadena 2 & Cadena 3 \\
\hline Número de talleres & 3 & 11 & 3 \\
\hline Proveedores involucrados & 21 & 96 & 24 \\
\hline Jornada laboral & $10-11$ horas & $8-16$ horas $^{5}$ & $10-17$ horas \\
\hline Frecuencia de producción & 2 veces por semana & $2-6$ veces por semana & 2 veces por semana \\
\hline Inversión diaria en la cadena & $\mathrm{C} \$ 2,447.95$ & $\mathrm{C} \$ 19,166.77$ & $\mathrm{C} \$ 3,888.10$ \\
\hline $\begin{array}{l}\text { Valor bruto de la } \\
\text { producción por semana }\end{array}$ & 11,250 & $\mathrm{C} \$ 247,500$ & $\mathrm{C} \$ 22,500$ \\
\hline $\begin{array}{l}\text { Empleos que genera } \\
\text { en el procesamiento }\end{array}$ & $\begin{array}{l}22 \text { personas } \\
M=18 \quad H=4\end{array}$ & $\begin{array}{l}130 \text { personas } \\
M=110 \quad H=20\end{array}$ & $\begin{array}{ll}26 \text { personas } & \\
\mathrm{M}=18 & \mathrm{H}=8\end{array}$ \\
\hline $\begin{array}{l}\text { Tipo de infraestructura } \\
\text { productiva }\end{array}$ & $\begin{array}{l}\text { - } 1 \text { horno por taller } \\
\text { costo:C\$ 3,000.00 } \\
\text {-Compra el servicio } \\
\text { de molino }\end{array}$ & $\begin{array}{l}\text { - } 1 \text { Molino por taller } \\
\text { Costo US\$ } 3,500 \\
1 \text { - } 5 \text { hornos por taller. } \\
\text { Costo: C\$ 2500-3000 }\end{array}$ & $\begin{array}{l}\text { - } 1 \text { Molino por taller } \\
\text { Costo: US } \$ 3,500.00 \\
\text { - 1- } 2 \text { hornos por taller } \\
\text { Costo: C } \$ 2500 \text { a } 3000\end{array}$ \\
\hline
\end{tabular}




\begin{tabular}{|l|l|l|c|}
\hline Ingreso Bruto diario por taller & $\mathrm{C} \$ 800.00$ a $1,600.00$ & $\mathrm{C} \$ 1,200.00 \mathrm{a} 5,000.00$ & $\mathrm{C} \$ 1,500.00 \mathrm{a} 2,500.00$. \\
\hline Ubicación de los talleres & Sectores 4,8 y 14 & Sectores 1,4 y 10 & Sector 4 \\
\hline
\end{tabular}

Fuente: elaboración propia sobre la base de entrevistas a las dueñas de los talleres.

En su conjunto, para la producción semanal, las cadenas mueven un valor bruto promedio de doscientos ochenta y un mil doscientos cincuenta córdobas (C\$281,250.00), equivalente a US\$ 19,396.55 dólares.

En el cuadro anterior, se puede ver que, en su conjunto, los talleres generan 178 empleos directos, más de seis empleos cada uno, por lo que, según los criterios del Instituto de la Pequeña y Mediana Empresa (INPYME), están en el rango de pequeñas empresas.

\subsection{Gobernabilidad de las cadenas}

A lo interno de cada cadena, hay algunos agentes que ejercen mayor poder que otros. Son el motor que dinamiza cada cadena. En la cadena 1, este papel se concentra en las dueñas de los talleres, ya que son ellas mismas quienes producen y venden; es decir, controlan ambas operaciones. En la cadena 2, el control se comparte entre las dueñas de los talleres y las intermediarias o vendedoras del mercado "Roberto Huembes", porque están más cerca de la demanda y buscan como vender más. Esta circunstancia implica una comunicación más fluida para los pedidos a las dueñas de los talleres, que ven en las vendedoras una oportunidad para incrementar su producción. En la cadena 3, el control es ejercido por las dueñas de los talleres, porque ellas deciden a quién entregar el producto para la venta y con quién continuar o no en la comercialización de las rosquillas.

\section{5 La organización en la producción}

La cadena 2 responde a un tipo de organización que permite mayor participación de actores, donde cada uno asume su rol con sentido de responsabilidad, haciéndola más efectiva y con mayores posibilidades de competencia. Hay una especie de especialización de los actores sociales ubicados en cada eslabón ${ }^{6}$.

En cambio, en la cadena 1, no hay separación entre el eslabón dos y tres de la cadena. Es la misma persona quien realiza el procesamiento y la comercialización. Esto en alguna medida limita la especialización de las actoras en una actividad concreta, por lo que los volúmenes de producción son menores.

En la cadena 3, si bien hay separación en los tres eslabones, son distintos actores los que realizan las actividades de cada eslabón. Estos actores no se ven a sí mismos como miembros de una cadena que, para funcionar eficientemente, depende de la forma en que cada actor asume la parte que le corresponde. 


\subsection{Ubicación de las cadenas en la economía}

El tema de la ubicación de esta actividad en la economía fue motivo de muchas reflexiones para entender por qué la producción de rosquillas es una actividad económica y por qué no lo es, llegando a la conclusión siguiente:

El concepto de economía informal, donde se ubica generalmente este tipo de actividad, socialmente ha tenido una connotación negativa que visualiza a estos sectores como surgidos de una economía en crisis, que sugiere desorden, bajos niveles de eficiencia, poca racionalidad, genera poco o ningún beneficio al país. En consecuencia, las personas del sector informal generalmente son excluidas del sector económico formal. Sin embargo, la mayoría de las mujeres productoras de rosquillas ejercen la actividad como su primer y único empleo.

Estas actividades económicas constituyen "una respuesta de la población ante la problemática del desempleo", pero generan importantes recursos al país e influyen significativamente en la proliferación del mercado y en la generación de un número de empleos que no registran las estadísticas oficiales.

Desde esta perspectiva, el concepto de informalidad queda superado porque los datos demuestran que los talleres son estables en su proceso de producción y comercialización ${ }^{7}$; generan un valor bruto de producción por semana que vale la pena tener en cuenta; y están soportados por una serie de relaciones sociales a lo interno que permite a cada cadena competir con otros productos como los meneitos, tortillitas y galletas, entre otros. Además, las personas que participan en la producción y comercialización de las rosquillas de Somoto han demostrado capacidad, energía y disposición en el desarrollo de esta actividad. En este sentido, considerar a este sector económico como "informal", lo limita y condiciona a seguir como está ${ }^{8}$.

No obstante, la connotación negativa no es el argumento principal para rechazar el enfoque, sino el hecho de que la actividad no es consecuencia de la economía de las últimas dos décadas, sino que tiene historia y raíz desde hace más de cinco décadas. Es decir: i) son informales en el sentido formal de la palabra, porque no están registradas, no pagan impuestos, no llevan registros contables, etc., ii) pero no lo son porque existen desde antes del modelo económico imperante; no sólo son comercio, sino que constituyen cadenas de producción y comercialización; y generan ganancias porque emplean directa e indirectamente a un importante número de personas que pueden resolver sus necesidades.

Los talleres de rosquillas son pequeñas empresas de la industria procesadora de alimentos, son realizadas manualmente y con tecnología tradicional-artesanal que operan en las unidades domésticas, utilizando mano de obra familiar y, cuando las necesidades de producción superan la mano de obra familiar, asalariados permanentes.

Tanto en el municipio de Somoto como en el resto del país, esta actividad no es considerada una actividad económica porque no aparece en las cuentas nacionales; no paga impuestos porque se considera que no genera los recursos económicos necesarios para ello; tampoco 
es sujeta de crédito porque algunas agencias financieras consideran que el tipo de gerencia que se ejerce en los talleres, no permite analizar si la actividad es rentable o no. El hecho de ser realizada en el ámbito doméstico es otro factor que influye negativamente.

En la sociedad existe una definición implícita y explícita sobre lo que es o no una actividad económica. Por definición, una actividad económica es la que tiene una participación en el mercado con importantes volúmenes de venta, empresas que poseen infraestructura y maquinarias exclusivamente diseñadas y construidas para el desarrollo de la producción a escala. De acuerdo a esta definición, la elaboración de rosquillas no puede ser considerada como actividad económica.

Sin embargo, existe una cantidad de pequeñas empresas que no reúnen necesariamente esos requisitos, pero dinamizan la economía del país: es el sector que más empleo genera y buena parte de los ingresos del Estado son percibidos principalmente de estas actividades. Pese a ello, son subestimadas porque no se reconoce su existencia e importancia como pequeñas empresas llenas de ingeniosidad, cuyo potencial vale la pena liberar para dar respuesta a los problemas económicos actuales.

Por lo anterior podemos afirmar que:

\section{Desde el punto de vista económico son formales}

- Los talleres son estables en su proceso de producción y comercialización. Generan un valor bruto de producción.

- Están soportados por una serie de relaciones sociales a lo interno que permite a cada cadena competir con las otras.

- Tienen una conexión con el mercado.

\section{Desde el punto de vista institucional son informales}

- No están inscritas legalmente, No pagan impuestos, Por el tipo de gerencia ejercida (no realizan registros contables)

\subsection{Los factores que influyen en la formación del precio}

Como en la mayoría de las actividades económicas, es en el mercado el escenario para la organización y para hacer propicia la actividad comercial (Mendoza, 1991: 243) donde se determina el precio de las rosquillas de Somoto. Hay inequidad entre las ganancias totales percibidas en el mercado y las percibidas en la producción. La tendencia es a que la brecha producción-comercialización se incremente.

Para lograr una distribución equitativa de las ganancias generadas a partir de esta actividad, -lejos de promover que las mujeres se dediquen a la comercialización de este producto-, el planteamiento consiste en proponer otro tipo de negociaciones, donde las productoras se apropien de la importancia de la actividad que realizan y de los ingresos que generan en el mercado, a los que tienen poco acceso. 
En los costos de producción, se incluye el costo de transporte, ya que las dueñas de los talleres pagan C\$ 25 córdobas por cada canasto enviado a Managua, en el que alcanzan 50 bolsas de rosquillas.

En la ilustración 2, se puede apreciar que, en la esfera de la comercialización, hay una amplia brecha en los ingresos percibidos producto de la venta de las rosquillas: son las comerciantes las que determinan los precios y términos de las relaciones de compra-venta (crédito, plazo de pago, cantidad, frecuencia de los pedidos, etc.), porque están en el mercado, donde se conoce mejor la demanda del producto. Ellas permiten que las rosquillas lleguen hasta el consumidor final

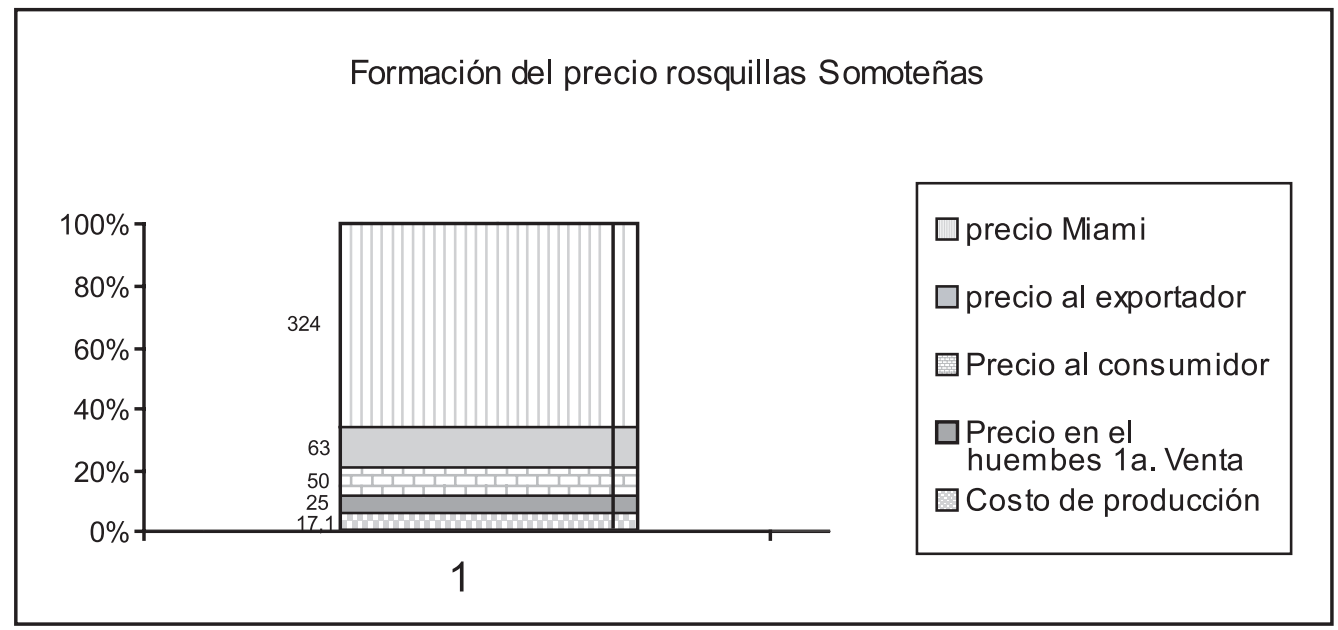

llustración 2. Formación del precio de las rosquillas somoteñas

\subsection{Los actores sociales participantes}

Según Mendoza (2002:10-11) los actores sociales son sabedores y capaces, tienen la habilidad de saber cuando es el momento apropiado para procesar información y diseñar estrategias para tratar con otros. Los principales actores que participan en las cadenas son:

Los proveedores de insumos: son, en su mayoría, hombres. Comerciantes mayoristas que se movilizan de un Municipio a otro para abastecer a sus clientes. También hay productores que tienen infraestructura para transformar productos, como los proveedores de cuajada y queso.

Las dueñas de los talleres: son todas mujeres; en su mayoría, casadas o acompañadas, lo que hace pensar que la condición de madre soltera no las ha motivado a realizar esa actividad.

Las comerciantes: son en su mayoría mujeres, salvo cuando la venta se realiza en El Salvador y Honduras, porque consideran que trasladarse hacia otro país, las obliga a ausentarse de sus casas y dejar a sus familias solas. En consecuencia, aseguran que es más fácil que lo 
hagan los hombres, ya que así la mujer queda al cuido de la familia, que es el "rol que le corresponde”.

En la siguiente ilustración se refleja el esquema de los principales actores sociales que participan en las cadenas:

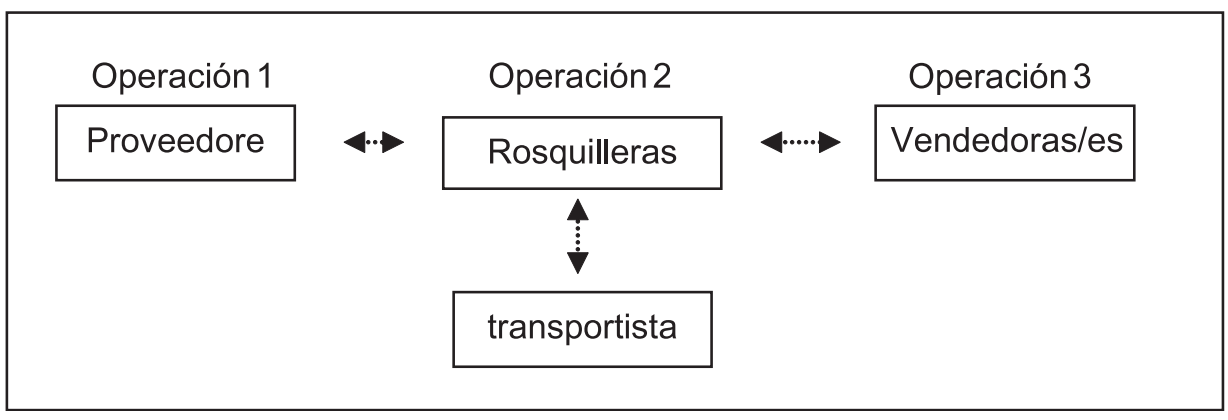

$70 \quad$ Ilustración 3. Principales actores que se relacionan en las cadenas

Fuente: elaboración propia sobre la base de entrevistas.

En cada operación de la cadena, hay diferentes tipos de relaciones sociales establecidas por actores sociales que se vinculan alrededor de una actividad particular. Estos actores establecen acuerdos que les permiten mantener la relación. Es decir: definen "las reglas del juego". Estas reglas o acuerdos se establecen de manera explícita y, en algunos casos, de manera implícita; tienen su base en el aprendizaje de experiencias positivas o negativas que han tenido con otras personas con quienes han hecho transacciones similares en diversos momentos. Por lo tanto, puede decirse que las relaciones son parte de una continuidad del aprendizaje que los diferentes actores adquieren.

Las relaciones que más frecuentemente se desarrollan a lo interno de las cadenas de comercialización de las rosquillas ocurren generalmente:

- El proveedor de queso o cuajada con la dueña del taller

- Entre la dueña del taller con la vendedora, fija o ambulante

- Entre la dueña del taller con el conductor del bus que traslada el producto a otro municipio

- Entre vendedoras

- Entre la dueña del taller con sus trabajadores

Una forma de ilustrar ese conjunto de relaciones sociales que ocurren en las cadenas lo sugiere la ilustración 4, donde la dueña del taller aparece como el centro de las relaciones con el resto de los actores. Las relaciones sociales que se producen no son iguales con todos los actores; desde la dueña del taller, se identifican relaciones primarias o estables para con algunos, mientras que con otros, las relaciones son secundarias: pueden desaparecer sin afectar el funcionamiento de la cadena porque son sustituidas de manera rápida con otros. 


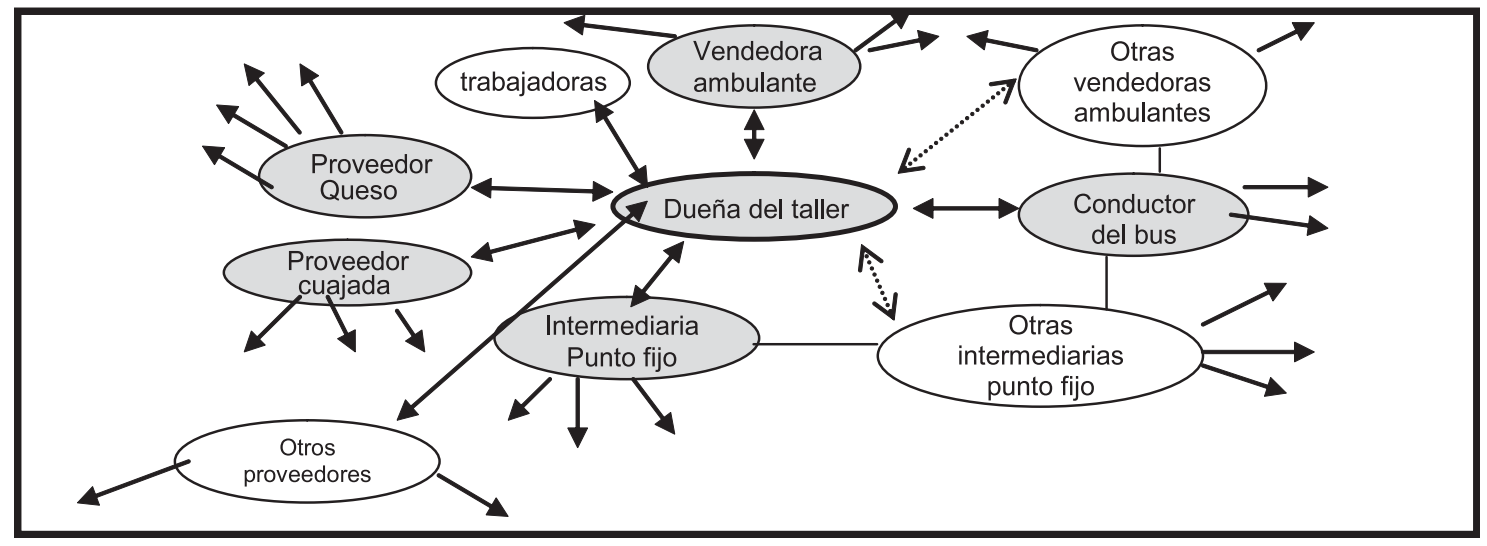

Ilustración 4. Esquema general de las relaciones encontradas

Fuente: elaboración propia sobre la base de entrevistas.

\subsection{Las relaciones encontradas}

Tipos de relaciones sociales que se producen en los casos estudiados

Caso1: Relación estable basada en la confianza, cooperación, solidaridad y comprensión. En este caso, se ubican los talleres de la cadena 1, donde más que existir compromiso con el incremento de la producción, los esfuerzos se dirigen a mantener los mismos niveles de producción y venta. Los participantes de esta cadena, para mantener las relaciones comerciales, utilizan estrategias como manejo de temas religiosos y sobredimensionan los problemas económicos de cada uno, para que el otro se sienta comprometido a seguir en la relación. Más que asumir eficientemente su rol respetando las reglas y acuerdos establecidos, proyectan un sentimiento de dependencia y hasta lástima, que motiva al otro (principalmente proveedores) a seguir en la relación. Estos elementos han sido efectivos para mantener la relación y para continuar realizando la actividad de producción de rosquillas.

Caso 2: Relaciones de compra-venta, prevaleciendo elementos como calidad y puntualidad. Este caso corresponde a la cadena 2 donde, a diferencia de la 1 y 3 , hay sentido de pertenencia, por lo que los actores asumen su rol con responsabilidad, porque están conscientes que de ello depende el funcionamiento de la cadena. Esto hace que la producción aumente constantemente con repercusiones ascendentes en toda la cadena.

Caso 3: Prevalecen relaciones de solidaridad y confianza por el rol de género y condición económica. En la cadena 3, hay sentido de pertenencia en los eslabones 1 y 2, por lo que el funcionamiento de la cadena, al menos hasta esa parte, es bueno. No obstante, en el eslabón 3 (comercialización), las mujeres que realizan venta del producto no tienen ese sentido de pertenencia. Esto ha significado bajos volúmenes de producción. 


\section{Discusión de resultados}

\subsection{Desde la informalidad, las mujeres son productoras de valor}

$\mathrm{Al}$ analizar las distintas actividades económicas del sector "informal", vemos que hay un predominio femenino, lo que demuestra que las mujeres siempre han estado vinculadas a la economía, pero invisibilizadas como consecuencia de estereotipos, mitos y tabúes.

Por lo anterior, la producción de rosquillas deteriora la autoestima de las mujeres, porque se considera como frustración y fracaso, por no desarrollar un trabajo reconocido socialmente como importante y digno. Que no solo genere ingresos económicos para pagar los gastos de su familia y la universidad de sus hijas/o, sino que además, genere respeto y orgullo.

En nuestra sociedad, incluyendo a las mujeres de los talleres de rosquillas, si una actividad es realizada por mujeres en el ámbito doméstico, y su gestión no incluye los términos contables prevalecientes, no es considerada como actividad económica y, por consiguiente, no es sujeta de crédito ni de asistencia técnica.

Sin embargo, pese a la ausencia de crédito, asistencia técnica y políticas de fomento, las cadenas de rosquillas ${ }^{9}$ existen y se vinculan a mercados internacionales. Su dinamismo ha provocado a nivel local, la emergencia de grupos de comerciantes que abastecen los talleres, además de la reciente instalación, con apoyo de un ONG, de una fábrica de queso.

\section{Los costos sociales para las mujeres}

Aunque las mujeres dirigen el proceso productivo y de comercialización, y la cadena 2, aparece como la más exitosa, es necesario analizar el costo social de esta actividad para las mujeres.

Al Trabajar en el ámbito doméstico, estas mujeres asumen, además de su rol doméstico como es el cuido de los y las hijas/os, el marido y la casa, la responsabilidad de la producción, lo que las obliga a desarrollar dobles y hasta triples jornadas laborales. combinando el trabajo productivo con el reproductivo.

Por lo tanto, la gerencia del negocio de las rosquillas se mezcla con la asunción de las responsabilidades del proceso de producción y con el mantenimiento y cuido del hogar, tres funciones que terminan agotando a las mujeres, porque que no pueden separar las funciones debido al rol de mujer socialmente asumido. En otro tipo de negocios, estas funciones estarían separadas y remuneradas; en los talleres, simplemente se asume.

\section{Por lo anterior, se puede afirmar que:}

i) En los talleres se produce una especie de autoexplotación, puesto que las mujeres desarrollan largas jornadas de trabajo que las terminan agotando y que se caracterizan por ser una especie de espiral o circulo vicioso que no termina nunca. Estos son los costos sociales y emocionales que significa para las mujeres la realización de dicha actividad. 
ii) Pese a que en la mayoría de los casos, la ganancia percibidas por las mujeres producto de la venta de las rosquillas es el único ingreso familiar porque el cónyuge se encuentra desempleado, este aporte no es valorado ni a lo interno del hogar ni en el municipio, pese a que genera empleos permanentes directos para unas 180 familias y otra cantidad importante de empleos indirectos.

iii) En los casos en que hay otro ingreso familiar, el aporte de la mujer es considerado como complementario, aunque sea mayor y cubra más de la mitad de las necesidades del hogar, incluso cuando cubre inversión en la infraestructura de la vivienda y los pagos de estudios universitarios de hijas e hijos. El aporte económico del hombre, aunque sea inferior, es considerado como el principal o básico, porque socialmente ha sido el proveedor económico (Pérez Sáinz y Menjívar Larín: 1993).

Por otro lado, la producción y comercialización de las rosquillas somoteñas ha sido, a lo largo de su historia, una actividad económica "ninguneada": se asume como una extensión de la actividad doméstica, es realizada por mujeres, está ubicada en una zona donde las principales actividades económicas se enfocan a la producción primaria (granos básicos, agricultura y ganadería) y la agroindustria en una escala menor; son las mujeres quienes llevan la mayor carga del trabajo en las tres operaciones de la cadena, desde la toma de decisiones sobre la cantidad a producir hasta la venta, mientras los hombres se dedican a las actividades que requieren de fuerza física.

Finalmente, este estudio revela la existencia de este sector que dinamiza la economía local, con predominio de presencia femenina, contribuyendo al análisis sobre la informalidad económica, la economía y las mujeres, inequidad de géneros o brecha entre estos.

\section{Conclusiones}

1. En un marco de comercio próximo a entrar al ALCA, este estudio revela al sector rosquillas, con predominio de participación femenina, como un sector que no existe para las políticas del gobierno ni para las agencias de cooperación, pero que es 15 veces más generador de capital y de empleo que, por ejemplo, el sector cuero-calzado.

2. Las cadenas funcionan como producto de las relaciones sociales entre actores sociales clave, quienes establecen alianzas para la producción y venta del producto.

3. Desde el punto de vista institucional, es doblemente subvalorada y no es considerada como una actividad económica por, al menos, tres razones que parecen evidentes:

a) Por estar ubicada en el ámbito doméstico

b) Porque no se ejerce el tipo de gerencia/contabilidad que prevalece en las grandes empresas

c) Por estar dirigida por mujeres 
4. La razón para que esta actividad persista, pese al contexto en que se desarrolla, es que las mujeres trabajan con recursos propios para solucionar sus necesidades inmediatas, más que por un interés de acumular.

5. Hay factores que favorecen la realización de la actividad:

a) la naturaleza del producto, al ser considerado un bien típico de identidad cultural que posee marca y asegura un mercado permanente a nivel nacional e internacional en la medida en que sigue el flujo migratorio de nicaragüenses que van a EU y Centroamérica.

b) el abastecimiento seguro de la materia prima, porque en el Municipio y en la región, el maíz es el principal rubro de producción.

c) el elemento de género: el hecho de que sea una actividad asumida por mujeres para garantizar el sustento de sus familias y la satisfacción de sus necesidades básicas, ha permitido la permanencia de esta actividad.

6. A lo largo del estudio queda demostrado que este sector de pequeña industria de alimentos generan un valor bruto de producción de C\$11,542,176.00 córdobas anuales.

7. Esta experiencia muestra que lo más decisivo para la permanencia de esta actividad ha sido el empeño y la disposición de las mujeres, la importancia que para ellas representa el ser jefas y tener una ocupación, aunque los costos físicos y emocionales no sean recompensados, más que el acceso a recursos externos y tecnología, entre otros.

8. Las cadenas de producción y comercialización de rosquillas son un modo de organización endógena que se perfecciona en la medida que sus participantes acumulan experiencias que les permiten implementar un modo de organización pertinente a su lógica y dinámica.

9. Es de relevancia señalar los costos que tiene para las mujeres la realización de la actividad: existe autoexplotación debido a que desarrollan largas jornadas laborales en los talleres, que se mezclan con la realización de labores domésticas y la crianza de hijas e hijos. Además, deben enfrentar la subvaloración de su trabajo por parte de los miembros de su familias y de la sociedad, provocando sentimientos de inferioridad y de fracaso personal, aunque son ellas quienes sostienen sus hogares.

\section{Recomendaciones}

1. Efectivamente los talleres están y se encuentran organizados. No obstante:

a. Es necesario que las dueñas realicen actividades que les permitan llegar al establecimiento de estrategias conjuntas y demandar servicios de apoyo a la expansión de su actividad, ante las Instituciones Estatales y ONGs. 
b. Se requiere establecer un precio estándar de venta al intermediario; es decir, "negociar el precio de las rosquillas" en mejores condiciones para las productoras.

2. Dado que las dueñas de los talleres son pequeñas empresarias llenas de creatividad e ingenio, es preciso liberar su potencialidad mediante políticas de incentivo y asistencia técnica para lograr un desarrollo que les permita, eventualmente, acumular ganancias e incursionar en segmentos de mercados masivos y de mayor poder adquisitivo.

3. En nuestro país existe un sinnúmero de actividades económicas con estas características, por lo que se hace necesario iniciar un debate que permita reconocer la existencia e importancia de este sector e incluirlo en los tratados de libre comercio, analizando previamente las ventajas y desventajas.

4. El motor principal para que el desarrollo sea autosostenido, sobre todo en países empobrecidos como el nuestro, es la generación y apoyo, en términos de políticas, de un tejido productivo bien articulado con el mercado, integrado principalmente por un sistema de pequeñas empresas locales que puedan valorar las potencialidades endógenas del área. Como es el caso estudiado.

5. Para desarrollar diferentes proyectos y/o actividades económicas, es importante tomar en cuenta la motivación e interés de las personas y no imponer desde afuera proyectos porque han tenido éxitos en otras realidades.

6. Continuar la realización de investigaciones sobre comercio con una perspectiva social, de manera que permita analizar y evidenciar las potencialidades que existen a nivel local y las formas de organizaciones que surgen desde la iniciativa de la población y que resultan exitosas para el desarrollo de sus localidades.

7. Dada la importancia del estudio y el sentimiento que prevalece entre las mujeres que participan de manera activa en el proceso productivo y de comercialización de rosquillas de Somoto, se hace necesario darles a conocer los resultados de este estudio como un primer esfuerzo dirigido a promover el reconocimiento de estas mujeres hacia la importancia de la actividad que realizan.

El siguiente paso corresponderle a instituciones estatales y ONGs interesados en realizar una labor de fortalecimiento a este sector, sin dejar de lado las propuestas e iniciativas de las propias mujeres, ya que son las que mejor conocen sus necesidades y posibles soluciones.

Notas

3 Producto hecho principalmente a base de maíz, cuajada, leche y margarina.

4 Los términos semi-integradas y desintegradas indican las operaciones de las cadenas. Si no están a cargo de la misma empresa, son desintegradas; si dos operaciones están a cargo de la empresa, es semi integrada; y si todas corren por cuenta de la misma empresa, entonces, de acuerdo a los planteamientos del análisis subsectorial, se les llaman integradas.

5 La jornada laboral no termina el mismo día, sino que se continúa el día siguiente. Realizan una especie de vigilia activa: todo el día 
viven en función de garantizar la producción.

6 Eslabón 1: abastecimiento, 2 procesamiento y 3 comercialización o venta del producto.

7 La economía informal supone que las actividades son inestables, que de la misma manera como surgen desaparecen, lo que no ocurre con las rosquillas.

8 Propicia la reproducción incluso de las mujeres, como actividad marginal que, lejos de proporcionar orgullo, produce frustración y lucha constante para que ningún miembro de la familia la siga realizando.

9 Son cadenas globalizadas. Surgen en un contexto ajeno a la globalización y se insertan a éste.

\section{Licenciaturas en}

\section{Sociología}

Una profesión con visión de futuro sobre la realidad social

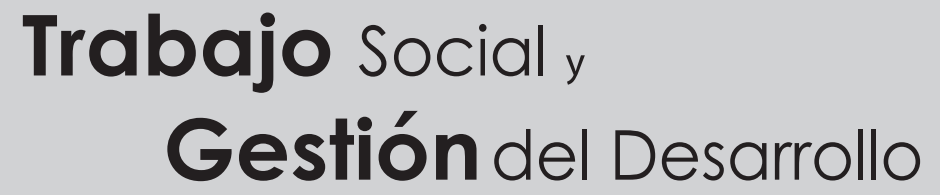

Una carrera fundamental para el desarrollo humano de Nicaragua

1. Pre-Matrícula : Octubre 2005 । Duración: $\mathbf{5}$ años

I Inicio clases: Febrero 2006 I Modalidad: Sabatina

\section{Campo Profesional}

- Organismos nacionales e internacionales

- Instituciones del estado y programas sociales

- Centros educativos y de investigación

- Gobiernos municipales y organizaciones locales

- Consultorías y asesorías

\section{Facultad de Humanidades \\ PBX 2783923 Ext. 255 ó 136 \\ E-mail:Iserra@ns.uca.edu.ni}

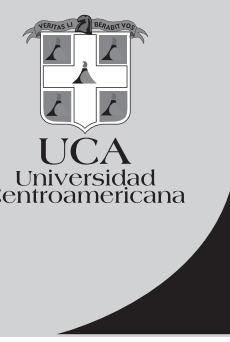

